14.2

\title{
Исследование токсического действия и проникновения в клетки монодисперсных сферических композитных частиц на основе мезопористого кремнезема
}

\author{
(C) С.В. Шмаков, ${ }^{1}$ В.В. Клименко, ${ }^{1}$ С.В. Коняхин, ${ }^{1}$ Д.А. Еуров, ${ }^{2}$ Д.А. Курдюков, ${ }^{2}$ В.Г. Голубев ${ }^{2}$ \\ ${ }^{1}$ Санкт-Петербургский академический университет РАН, \\ 194021 Санкт-Петербург, Россия \\ ${ }^{2}$ Физико-технический институт им. А.Ф. Иофффе РАН, \\ 194021 Санкт-Петербург, Россия \\ e-mail: stas-svs@list.ru
}

(Поступило в Редакцию 29 декабря 2017г.)

На основе монодисперсных сферических мезопористых частиц кремнезема (МСМЧК) синтезированы композитные частицы посредством нековалентного связывания органических активных компонентов (флуоресцентный краситель иодистый пропидий и фотосенсибилизатор Радахлорин) из водных растворов. Синтезированы гибридные частицы со структурой ядро-оболочка, которые представляют собой МСМЧК, заполненные $\mathrm{Fe}_{3} \mathrm{O}_{4}$ и покрытые оболочкой мезопористого кремнезема, внутренняя поверхность которой модифицирована люминофором FITC посредством хемосорбции. Исследована токсичность и проникновение в клетки полученных частиц на клеточных культурах HeLa и K-562. Продемонстрировано эффективное фотодинамическое действие МСМСК, содержащих в мезопорах Радахлорин, что свидетельствует о перспективности применения синтезированных композитных частиц для медицинских целей.

DOI: 10.21883/JTF.2018.09.46421.2631

\section{Введение}

Коллоидные частицы мезопористого кремнезема в настоящее время находят широкое применение в информационных технологиях, биологии, контроле состояния окружающей среды [1]. Возможность модификации размера и формы мезопористых частиц кремнезема (МЧК), a также функционализации внутренней и внешней поверхностей открывают перспективу их применения в биомедицине в качестве маркеров и наноконтейнеров для токсичных лекарственных препаратов [2-5]. На основе МЧК разрабатываются системы адресной доставки лекарств в опухоль $[3,5,6]$, флуоресцентные и магнитные метки для диагностики $[3,5]$.

В последние годы в медицине активно развивается новый подход к лечению онкологических заболеваний, получивший название тераностика, заключающийся в создании препаратов, которые объединяют в себе как терапевтическую, так и диагностическую функции. Использование таких препаратов позволит значительно повысить эффективность лечения [5,7]. Монодисперсные сферические мезопористые частицы кремнезема (МСМЧК) [8-13] благодаря своим уникальным свойствам (большие удельная поверхность и объем пор, внутренняя подсистема наноканалов одинакового диаметра, возможность контролируемого варьирования размера частиц, сферическая форма, биосовместимость) являются идеальной матрицей для создания многофункциональных композитных частиц, перспективных для применения в тераностике.

Монодисперсные сферические мезопористые частицы кремнезема обычно синтезируют с использованием в ка- честве порообразующих веществ молекул алкиламинов, которые затем удаляют из пор с помощью отжига [8-12]. Получаемые таким способом МСМЧК являются биосовместимыми и нетоксичными [3,14]. Американское агентство по контролю пищевых продуктов и лекарственных средств (US Food and Drug Administration) признало МЧК безопасным материалом ("Generally Recognized As Safe“), они входят в состав лекарств и косметических средств $[15,16]$. Однако при создании на основе МСМЧК композитных частиц, содержащих в порах органический или неорганический активный компонент, или гибридных частиц со структурой ядро-оболочка, токсичность получаемых частиц может возрастать. Токсичность может возникать из-за неполного удаления токсичных реагентов, применяемых при синтезе частиц. Кроме того, состав композитных и гибридных частиц может влиять на способность наночастиц проникать через плазматическую мембрану клеток. Поэтому необходим контроль токсичности и проникновения в клетки получаемых многофункциональных частиц.

В настоящей работе методом нековалентного связывания (физической адсорбции) получены монодисперсные сферические композитные частицы (МСКЧ), содержащие в мезопорах краситель иодистый пропидий $\left(m \mathrm{SiO}_{2} / \mathrm{PI}\right)$ и фотосенсибилизатор Радахлорин ( $\mathrm{mSiO}_{2} /$ Radachlorin). Получены гибридные частицы, представляющие собой МСМЧК, заполненные магнетитом и покрытые оболочкой мезопористого кремнезема $\left(m \mathrm{SiO}_{2}\right)$, ковалентно модифицированной (посредством хемосорбции) красителем флуоресцеин изотиоцианатом FITC $\left(m \mathrm{SiO}_{2} / \mathrm{Fe}_{3} \mathrm{O}_{4} @ m \mathrm{SiO}_{2} / \mathrm{FITC}\right)$. Исследована токсич- 
ность и проникновение в клетки полученных частиц на клеточных культурах HeLa и K-562. Продемонстрировано усиление фотодинамического эффекта частиц $m \mathrm{SiO}_{2} /$ Radachlorin по сравнению с раствором Радахлорина.

\section{1. Образцы и методы исследования}

Монодисперсные сферические мезопористые частицы кремнезема синтезированы гидролизом тетраэтоксисилана в спирто-водно-аммиачной среде, содержащей поверхностно-активный структурообразующий агент цетилтриметиламмоний бромид $[10,12,13]$. Методика синтеза обеспечивает получение МСМЧК с контролируемо варьируемым средним диаметром в диапазоне от 50 до $1500 \mathrm{~nm}$. В работе приведены результаты для МСМЧК диаметром $200 \pm 15 \mathrm{~nm}$. Частицы являются агрегативно устойчивыми в слабокислых и основных средах, изоэлектрическая точка находится при $\mathrm{pH} \sim 3$ [12]. Внутри частиц имеется система плотноупакованных монодисперсных цилиндрических пор диаметром $3.1 \pm 0.2 \mathrm{~nm}$. Объемная доля пор составляет 50 vol.\% от объема частиц, удельная поверхность частиц равна $750 \mathrm{~m}^{2} / \mathrm{g}$. Дзета-потенциал частиц и их распределение по размерам измерялись на приборе ZetaSizer Nano ZS (Malvern Instruments, Великобритания). Размеры пор и удельная поверхность частиц определялись методом адсорбционной порометрии с использованием азота в качестве адсорбата на приборе ASAP 2020 (Micromeritics, CША).

Монодисперсные сферические гибридные частицы (МСГЧ) со структурой ядро-оболочка на основе оксидов железа и кремния $\left(m \mathrm{SiO}_{2} / \mathrm{Fe}_{3} \mathrm{O}_{4} @ m \mathrm{SiO}_{2}\right)$ были синтезированы по методике, описанной в работах $[17,18]$. Сначала в поры МСМЧК вводился $\alpha$ - $\mathrm{Fe}_{2} \mathrm{O}_{3}$ путем однократной пропитки пор расплавом кристаллогидрата нитрата железа и его последующей термодеструкции. Затем восстановлением в водороде при $350^{\circ} \mathrm{C}$ в термодинамически равновесных условиях из $\alpha-\mathrm{Fe}_{2} \mathrm{O}_{3}$ в порах были синтезированы нанокластеры $\mathrm{Fe}_{3} \mathrm{O}_{4}$ [17]. Степень заполнения магнетитом составила $30 \mathrm{vol} \%$ от объема композитных частиц. Далее частицы $m \mathrm{SiO}_{2} / \mathrm{Fe}_{3} \mathrm{O}_{4}$ покрывались оболочкой мезопористого кремнезема $[17,19]$. Частицы $m \mathrm{SiO}_{2} / \mathrm{Fe}_{3} \mathrm{O}_{4}$ диспергировались в смеси, содержащей структурообразующий агент, деионизованную воду, аммиак и этанол, затем добавлялся тетраэтоксисилан. Состав смеси и условия синтеза обеспечивали нанесение на частицы оболочек $m \mathrm{SiO}_{2}$ одинаковой толщины. Диаметр гибридных частиц $m \mathrm{SiO}_{2} / \mathrm{Fe}_{3} \mathrm{O}_{4} @ m \mathrm{SiO}_{2}$ составил $255 \pm 20 \mathrm{~nm}$. Для удаления органики синтезированные МСГЧ отмывались в спиртовом растворе $\mathrm{HCl}$ $(0.001 \mathrm{M})$, затем высушивались на воздухе при температуре $100^{\circ} \mathrm{C}$. Удельная поверхность и объем пор полученных МСГЧ составили $250 \mathrm{~m}^{2} / \mathrm{g}$ и $0.15 \mathrm{~cm}^{3} / \mathrm{g}$ соответственно [17].
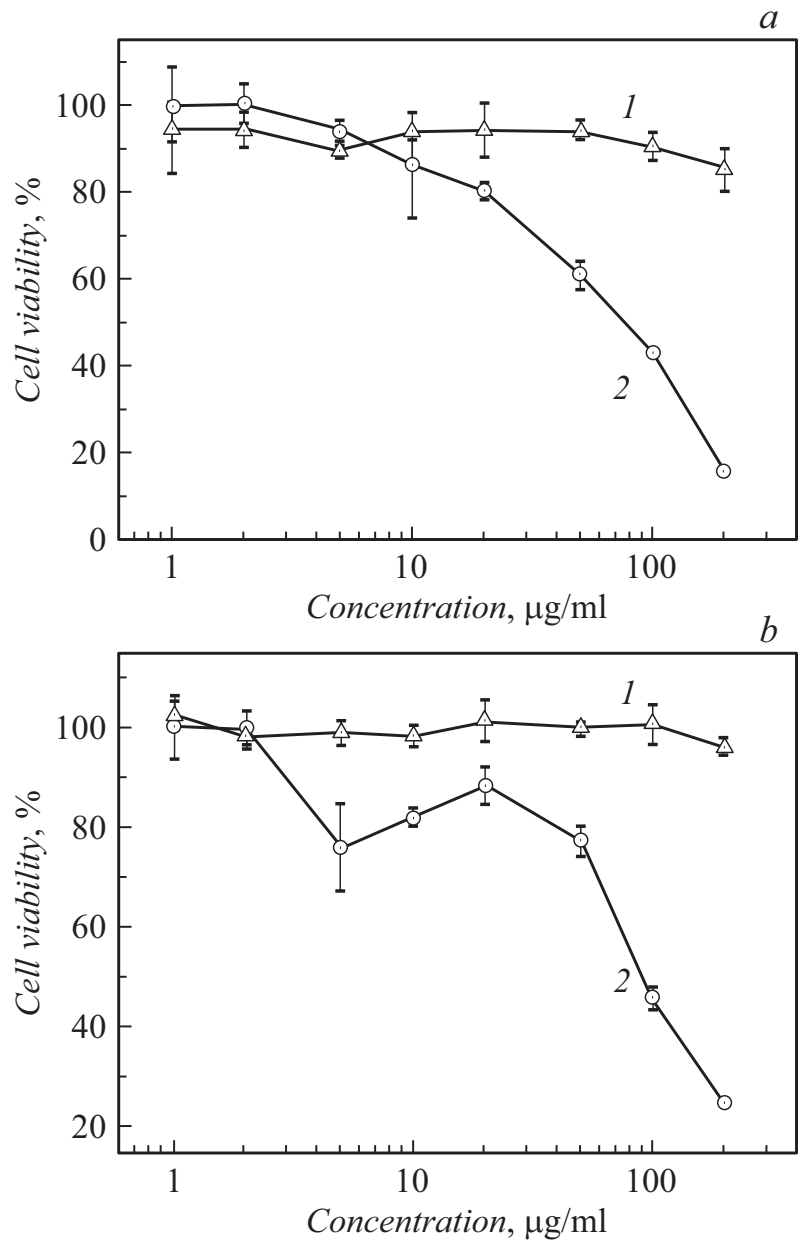

Рис. 1. Выживаемость клеток K-562 (a) и HeLa (b) через $24 \mathrm{~h}$ при воздействии частиц $m \mathrm{SiO}_{2} / \mathrm{Fe}_{3} \mathrm{O}_{4} @ m \mathrm{SiO}_{2} / \mathrm{FITC}(1)$ и $m \mathrm{SiO}_{2} / \mathrm{Fe}_{3} \mathrm{O}_{4} @ m \mathrm{SiO}_{2}(2)$.

Для придания частицам $m \mathrm{SiO}_{2} / \mathrm{Fe}_{3} \mathrm{O}_{4} @ m \mathrm{SiO}_{2}$ люминесцентных свойств была проведена модификация поверхности пор оболочки флуоресцеин изотиоцианатом посредством хемосорбции. Модификация пор FITC осуществлялась в два этапа. На первом этапе силанольные группы в оболочке частиц $m \mathrm{SiO}_{2} / \mathrm{Fe}_{3} \mathrm{O}_{4} @ m \mathrm{SiO}_{2}$ замещались $\mathrm{NH}_{2}$-группами аналогично процедуре, описанной в работе [20]. После этого частицы отжигались при температуре $100^{\circ} \mathrm{C}$ в течение $2 \mathrm{~h}$. На втором этапе проводилась хемосорбция FITC поверхностными аминогруппами из спиртового раствора FITC с концентрацией $10 \mathrm{mM}$ в течение 2 day. Затем частицы $m \mathrm{SiO}_{2} / \mathrm{Fe}_{3} \mathrm{O}_{4} @ m \mathrm{SiO}_{2} / \mathrm{FITC}$ отделялись центрифугированием и промывались деионизованной водой (с сопротивлением $10 \mathrm{M} \Omega$ ) для удаления неспецифически связанного FITC. Оставшиеся внутри частиц молекулы FITC были химически (ковалентно) связаны с поверхностью пор в оболочке.

В настоящей работе также реализовано нековалентное связывание МСМЧК со стандартным красителем для цитологических исследований (иодистым пропидием) и отечественным высокоэффективным фотосен- 

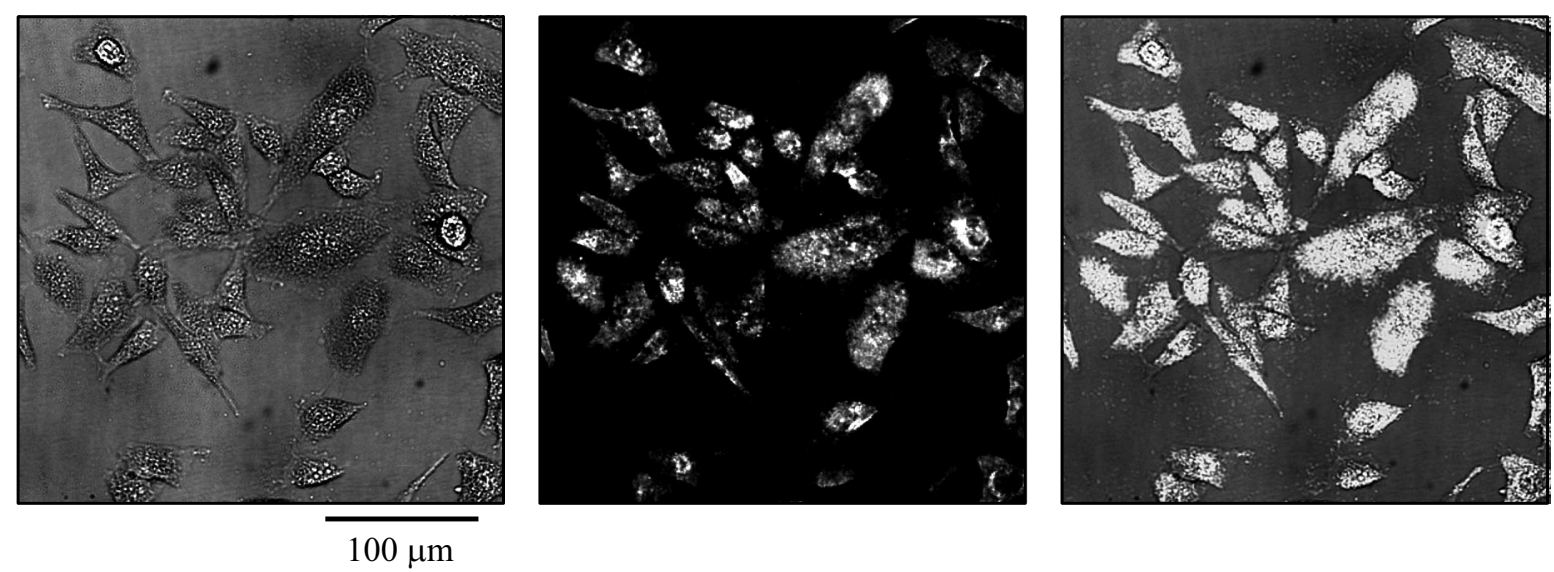

$100 \mu \mathrm{m}$

Рис. 2. Накопление частиц $m \mathrm{SiO}_{2} / \mathrm{Fe}_{3} \mathrm{O}_{4} @ m \mathrm{SiO}_{2} / \mathrm{FITC}$ в клетках HeLa. Левое изображение демонстрирует клетки в оптическом канале, центральное - во флуоресцентном, на правом представлено наложение каналов.

сибилизатором Радахлорином [21-23]. Количество физически адсорбированного (нековалентно связанного) компонента определялось спектрофотометрическим методом с использованием спектрофотометра NanoDrop 2000c (Thermo Scientific, США, длина оптического пути $l=1 \mathrm{~mm})$.

Частицы $m \mathrm{SiO}_{2} / \mathrm{PI}$ и $m \mathrm{SiO}_{2} /$ Radachlorin приготавливались следующим образом. К $200 \mu \mathrm{L}$ водной суспензии МСМЧК $(C=2 \mathrm{mg} / \mathrm{mL})$ добавлялось $5 \mu \mathrm{L}$ иодистого пропидия (PI, Sigma, CША; $C=1 \mathrm{mg} / \mathrm{mL}$ ) или Радахлорина (Рада-Фарма, Россия; $C=1 \mathrm{mg} / \mathrm{mL}$ ) соответственно. Полученная смесь инкубировалась $24 \mathrm{~h}$, при этом соответствующий активный компонент адсорбировался внутренней поверхностью пор МСМЧК. Затем частицы осаждались центрифугированием при ускорении $3000 \mathrm{~g}$ в течение $30 \mathrm{~min}$. В качестве образцов сравнения готовились контрольные растворы, содержащие $200 \mu \mathrm{L}$ деионизованной воды с $5 \mu \mathrm{L}$ PI и Радахлорина таких же концентраций. Количество адсорбированного частицами вещества определялось по разнице величины оптического поглощения контроля с супернатантом.

Для исследования токсичности и оценки способности частиц проникать через плазматическую мембрану использовались клеточные линии карциномы шейки матки HeLa и хронической миелогенной лейкемии K-562. Клетки были получены из Российской коллекции клеточных культур (Институт цитологии РАН, СанктПетербург). Клетки HeLa культивировались при $37^{\circ} \mathrm{C}$ в среде DMEM (HyClone, США), содержащей 10\% эмбриональной бычьей сыворотки (HyClone, США), в присутствии антибиотика гентамицина (Биолот, Россия) в атмосфере, содержащей 5\% $\mathrm{CO}_{2}$. Клетки К-562 культивировались в среде RPMI-1640 (HyClone, CША), содержащей $10 \%$ эмбриональной бычьей сыворотки в присутствии гентамицина, в аналогичных условиях.

Токсичность частиц анализировалась с помощью колориметрического анализа (MTS-тест) по стандартному протоколу: клетки рассеивались в микротитрационный 96-луночный планшет в количестве 10000 клеток/лунка, планшет инкубировался $24 \mathrm{~h}$ в $\mathrm{CO}_{2}$-инкубаторе, затем к клеткам добавлялось исследуемое вещество. Через $24 \mathrm{~h}$ в лунки добавлялось по $20 \mu \mathrm{L}$ MTS-реагента (BioVision, США), после этого планшет дополнительно инкубировался 2 h. Полученные результаты анализировались на планшетном спектрофотометре Multiskan GO (Thermo Scientific, США).

Оценка проникновения и накопления частиц в клетки проводилась с помощью конфокального флуоресцентного микроскопа Zeiss AxioObserver Z1 (Zeiss, Германия). Флуоресценция PI $\left(\lambda_{\mathrm{ex}} / \lambda_{\mathrm{em}}=493 / 636 \mathrm{~nm}\right)$ и FITC $\left(\lambda_{\mathrm{ex}} / \lambda_{\mathrm{em}}=492 / 520 \mathrm{~nm}\right)$ возбуждалась $\mathrm{Ar}^{+}$лазером с длиной волны $\lambda_{\max }=488 \mathrm{~nm}$, регистрация сигнала флуоресценции осуществлялась с использованием оптического фильтра $520 / 50 \mathrm{~nm}$. Фотодинамическое воздействие осуществлялось с помощью лазера с длиной волны излучения $\lambda=662 \mathrm{~nm}$.

\section{2. Результаты работы и обсуждение}

\section{1. Токсичность и накопление внутри клеток композитных частиц с оболочкой мезопористого кремнезема}

Результаты исследования выживаемости клеток при воздействии на них частиц $m \mathrm{SiO}_{2} / \mathrm{Fe}_{3} \mathrm{O}_{4} @ m \mathrm{SiO}_{2}$ и $m \mathrm{SiO}_{2} / \mathrm{Fe}_{3} \mathrm{O}_{4} @ m \mathrm{SiO}_{2} / \mathrm{FITC}$ представлены на рис. 1. Частицы, содержащие FITC в порах оболочки $\mathrm{mSiO}_{2}$, нетоксичны во всем интервале концентраций. В то же время для МСГЧ, оболочка которых не содержит люминофора, наблюдается увеличение токсичности (рис. $1, b)$. Однако частицы не оказывают негативного влияния на клетки при концентрациях, пригодных для фармакологических применений (концентрация полумаксимального ингибирования $\mathrm{IC}_{50}$ составляет $\sim 100 \mu \mathrm{g} / \mathrm{mL}$ для обеих клеточных культур K-562 и HeLa). Например, с помощью магнитных полей частицы с ядром, содержащим магнетит, могут быть локально сконцентрированы в требуемой 

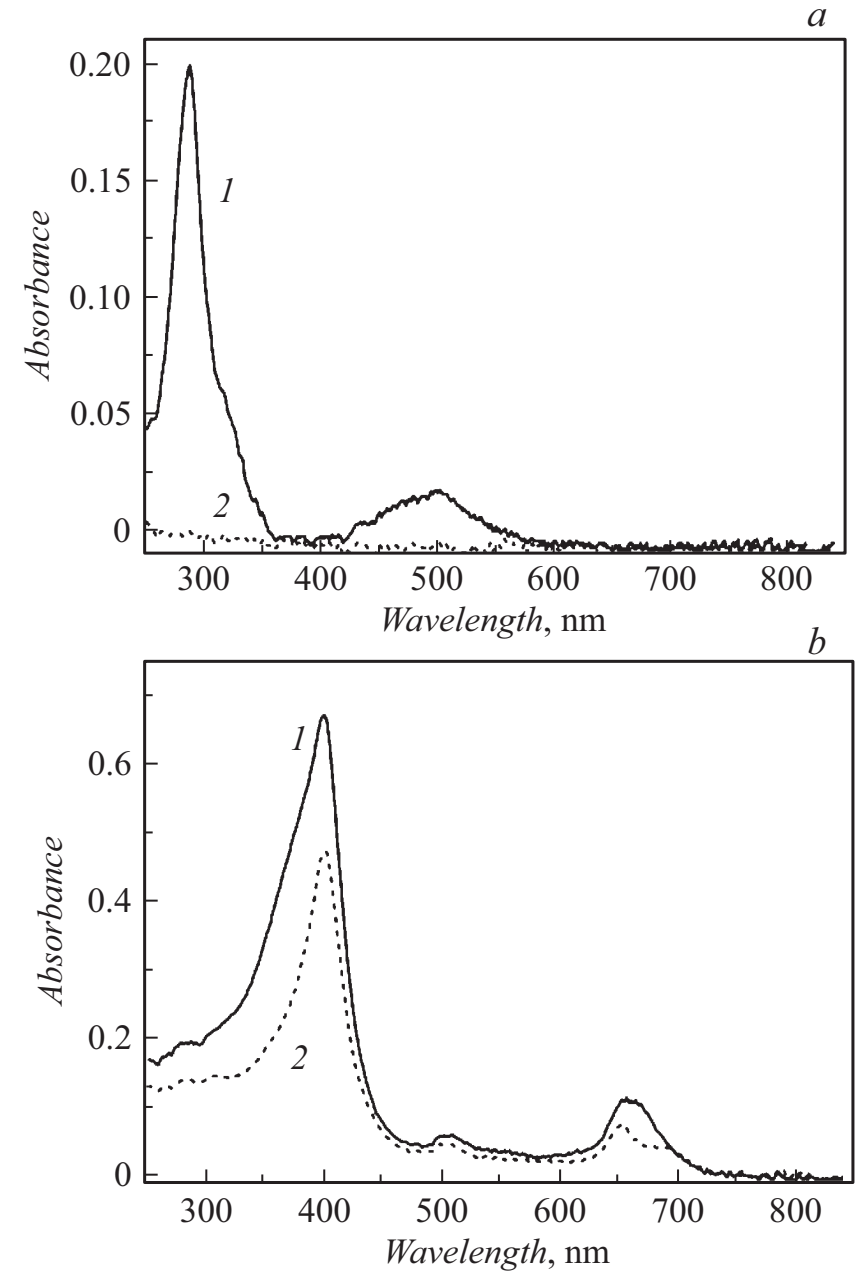

Рис. 3. Спектры оптического поглощения: $a-$ флуоресцентный краситель иодид пропидия: 1 - водный раствор $(C=25 \mu \mathrm{g} / \mathrm{mL}), 2-$ супернатант после нековалентного связывания РІ частицами $m \mathrm{SiO}_{2} . b-$ фотосенсибилизатор Радахлорин: $1-$ водный раствор $(C=50 \mu \mathrm{g} / \mathrm{mL}), 2-$ супернатант после нековалентного связывания Радахлорина частицами $m \mathrm{SiO}_{2}$.

области [24], что в перспективе позволит осуществить их адресную доставку.

Рассмотрим подробнее возможные причины возникновения токсичности частиц $m \mathrm{SiO}_{2} / \mathrm{Fe}_{3} \mathrm{O}_{4} @ m \mathrm{SiO}_{2}$. Наноразмерные частицы магнетита $\mathrm{Fe}_{3} \mathrm{O}_{4}$ обладают низкой токсичностью и могут метаболизироваться организмом $[25,26]$. Технологическая схема введения наночастиц магнетита в поры МСМЧК включает этап, в котором проводится термообработка при $350^{\circ} \mathrm{C}$ в водороде в течение $20 \mathrm{~h}$ [17]. Во время такой длительной температурной обработки композитные частицы очищаются от возможных примесей, поэтому частицы $m \mathrm{SiO}_{2} / \mathrm{Fe}_{3} \mathrm{O}_{4}$ нетоксичны. Токсичность частиц $m \mathrm{SiO}_{2} / \mathrm{Fe}_{3} \mathrm{O}_{4} @ m \mathrm{SiO}_{2}$ может объясняться различием технологии изготовления мезопористого кремнезема оболочки и кремнезема в исходных МСМЧК. Так, при синтезе нетоксичных МСМЧК органические порообразующие веще- ства удалялись из пор с помощью отжига на воздухе при $550^{\circ} \mathrm{C}[10,12]$, а из $\mathrm{mSiO}_{2}$ оболочки гибридных частиц алкиламины удалялись растворением в спиртовом растворе $\mathrm{HCl}$. По-видимому, вследствие высокой адсорбционной способности $m \mathrm{SiO}_{2}$ (см. разд. 2.2) следы порообразующих веществ могли остаться в порах, что и вызвало увеличение токсичности. Затем в ходе ковалентной модификации флуорофором FITC и последующей очистки (см. разд. 1) токсичные вещества были удалены из пор оболочки посредством многократной промывки, и поэтому частицы $m \mathrm{SiO}_{2} / \mathrm{Fe}_{3} \mathrm{O}_{4} @ m \mathrm{SiO}_{2} / \mathrm{FITC}$ вновь стали нетоксичными.

Оптическое и флуоресцентное изображение, демонстрирующее проникновение и накопление в клетках частиц $m \mathrm{SiO}_{2} / \mathrm{Fe}_{3} \mathrm{O}_{4} @ m \mathrm{SiO}_{2} / \mathrm{FITC}$, представлено на рис. 2 . Видно, что частицы локализованы в цитоплазме, интенсивность флуоресцентного сигнала в ядре несколько снижена, что объясняется ослабленным проникновением наночастиц сквозь ядерную мембрану. Морфология клеток не отличается от нормальной, что свидетельствует об отсутствии выраженного токсического действия.

\section{2. Нековалентное связывание иодистого пропидия и Радахлорина с частицами кремнезема и проникновение композитных частиц в клетки}

Результаты экспериментов по нековалентному связыванию кремнеземных наночастиц с иодистым пропидием и Радахлорином представлены на рис. 3. Как видно из рис. 3, $a$, в супернатанте отсутствуют пики поглощения на длинах волн 290 и $493 \mathrm{~nm}$, характерные для иодида пропидия. Следовательно, иодистый пропидий из водного раствора с концентрацией $25 \mu \mathrm{g} / \mathrm{mL}$ полностью адсорбируется суспензией МСМЧК с концентрацией $2 \mathrm{mg} / \mathrm{mL}$. Такое эффективное нековалентное связывание может объясняться кулоновским взаимодействием между катионом пропидия $\left[\mathrm{C}_{27} \mathrm{H}_{34} \mathrm{~N}_{4}\right]^{2+}$ и отрицательно заряженными вследствие диссоциации силанольными группами на поверхности пор МСМЧК (дзета-потенциал $\xi=-30 \mathrm{mV}$ ). Молекулы Радахлорина полярны, что также позволяет им эффективно связываться с внутренней поверхностью МСМЧК в результате электростатических и/или ван-дер-ваальсовых взаимодействий. Вследствие меньшего по сравнению с PI эффективного положительного заряда Радахлорин не полностью адсорбируется МСМЧК (рис. $3, b$ ).

На рис. 4 представлены фотографии, на которых демонстрируется внутриклеточная доставка иодистого пропидия, находящегося в мезопорах МСМЧК. Иодистый пропидий не способен проникать через неповрежденную мембрану живых клеток. В случае проникновения через мембрану (например, мертвых клеток), PI связывается с ДНК, находящимся в ядре.

Рис. 4, $a$ демонстрирует, что флуоресцентный сигнал внутри клеток не наблюдается, поскольку катионы PI 

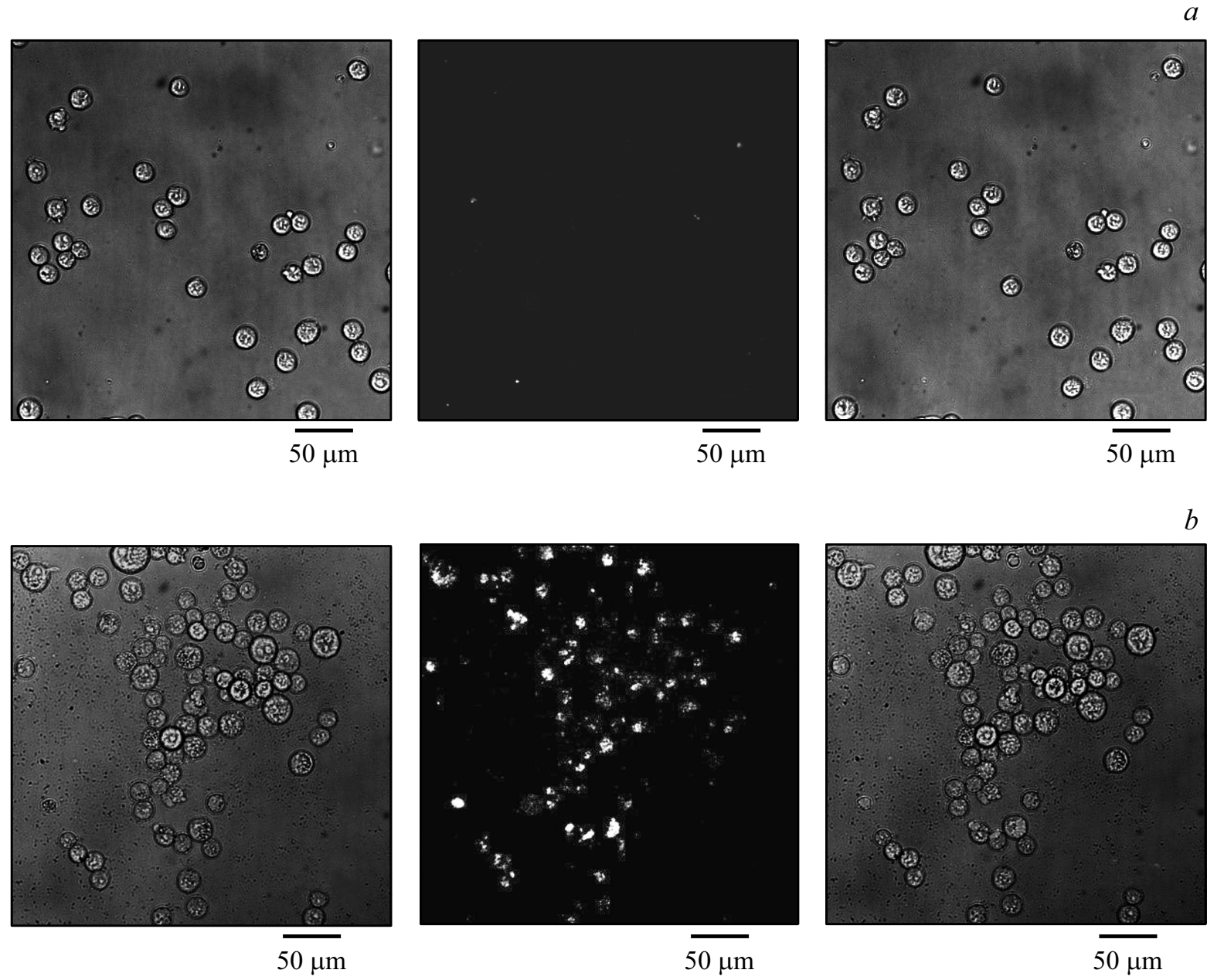

Рис. 4. Проникновение в клетки К-562 флуоресцентного красителя иодистого пропидия: $a-$ водный раствор PI, $b-$ водная суспензия монодисперсных сферических композитных частиц $m \mathrm{SiO}_{2} / \mathrm{PI}$. В левой части рисунков представлено оптическое изображение клеток, в центральной - флуоресцентный канал, справа приведено их наложение.

из водного раствора не проникают в клетки. Рис. 4, $b$ подтверждает проникновение красителя, находящегося в порах композитных частиц $m \mathrm{SiO}_{2} / \mathrm{PI}$, через мембрану живых клеток. В клетках детектируется флуоресценция PI, который локализован в цитоплазме. Отсутствие флуоресценции в ядрах и отсутствие морфологических отличий клеток, содержащих частицы $\mathrm{mSiO}_{2} / \mathrm{PI}$, от контроля свидетельствует о том, что композитные частицы не оказывают токсического действия. В исследуемой суспензии композитных частиц концентрация $m \mathrm{SiO}_{2}$ составила $10 \mu \mathrm{g} / \mathrm{mL}$, концентрация PI была равна $0.65 \mu \mathrm{g} / \mathrm{mL}$.

\section{3. Фотодинамическое действие композитных частиц кремнезема с Радахлорином}

Фотосенсибилизатор Радахлорин в отличие от иодида пропидия может проникать через мембрану живых клеток. Представленная ранее [22,23] противоопухолевая эффективность фотодинамической терапии с использованием Радахлорина делает актуальным вопрос о разработ- ке для него эффективной системы инкапсуляции и адресной доставки, которая позволит осуществить локальное концентрирование молекул фотосенсибилизатора внутри клеток и повысить эффективность терапии. Поэтому в настоящей работе были проведены эксперименты по практической реализации фотодинамического эффекта МСКЧ $m \mathrm{SiO}_{2} /$ Radachlorin на клеточной культуре К-562.

Рис. 5 демонстрирует усиление фотодинамического действия МСКЧ $\mathrm{mSiO}_{2} /$ radachlorin, по сравнению с водным раствором Радахлорина. Клетки инкубировались $24 \mathrm{~h}$ и после этого были облучены лазером $(\lambda=662 \mathrm{~nm})$. Доза излучения составила $2 \mathrm{~J} / \mathrm{cm}^{2}$, концентрация Радахлорина - $10 \mu \mathrm{g} / \mathrm{mL}$. На изображениях видно повреждение клеточной мембраны, проявляющееся в виде возникновения характерных пузырьков. Композитные частицы $m \mathrm{SiO}_{2} /$ Radachlorin вызывают значительно большее изменение морфологии клеток по сравнению с водным раствором фотосенсибилизатора. Такой эффект может объясняться большей степенью локализации Радахлорина, связанного с частицами на плазматической мембране и других органеллах, по сравнению со свобод- 

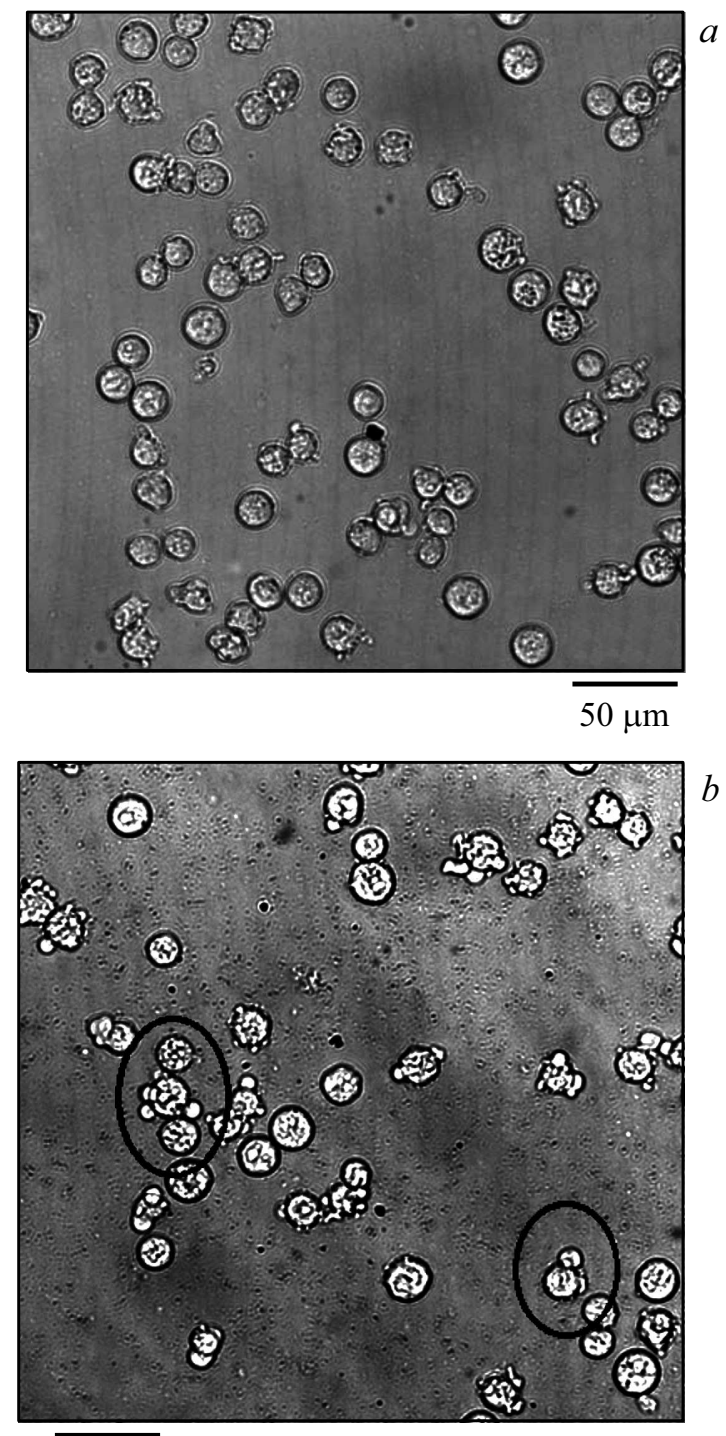

$50 \mu \mathrm{m}$

Рис. 5. Фотографии клеток, обработанных водным раствором фотосенсибилизатора Радахлорина $(a)$ и композитными частицами $m \mathrm{SiO}_{2} /$ Radachlorin $(b)$, и подвергнутых облучению лазера с длиной волны $\lambda=662 \mathrm{~nm}$. Одинаковые дозы излучения вызывают различный эффект: в случае свободного фотосенсибилизатора изменения морфологии не наблюдаются, в то время как композитные частицы $m \mathrm{SiO}_{2} /$ Radachlorin вызывают выраженные нарушения морфологии (возникновение пузырьков)

ным фотосенсибилизатором, молекулы которого более равномерно распределяются по цитоплазме.

\section{Заключение}

Синтезированы монодисперсные композитные частицы методом нековалентного связывания флуоресцентного красителя иодистого пропидия и фотосенсибилизатора Радахлорина с химически активной внутренней поверхностью МСМЧК. Синтезированы гибридные частицы со структурой ядро-оболочка, которые представляют собой МСМЧК, заполненные $\mathrm{Fe}_{3} \mathrm{O}_{4}$ и покрытые оболочкой мезопористого кремнезема, внутренняя поверхность которой модифицирована люминофором FITC посредством хемосорбции.

На клеточных культурах HeLa и K-562 исследована токсичность гибридных частиц до модификации пор оболочки FITC. Концентрация полумаксимального ингибирования $\mathrm{IC}_{50}$ составила $\sim 100 \mu \mathrm{g} / \mathrm{mL}$ для обеих культур. Показано, что данные частицы после ковалентной модификации поверхности пор FITC становятся нетоксичными во всем диапазоне исследуемых концентраций.

Продемонстрировано, что гибридные частицы со структурой ядро-оболочка, модифицированные FITC, проникают через клеточную мембрану и накапливаются в клетках HeLa. Выявлена способность частиц мезопористого кремнезема доставлять иодид пропидия через плазматическую мембрану клеток культуры К-562.

Продемонстрировано усиление фотодинамического эффекта Радахлорина, адсорбированного внутренней поверхностью пор МСМЧК, по сравнению со свободным фотосенсибилизатором. Концентрация МСМЧК, осуществляющих внутриклеточную доставку Радахлорина в эффективной для фотодинамической терапии концентрации, на порядок ниже величины их $\mathrm{IC}_{50}$, что свидетельствует о потенциальной возможности применения синтезированных композитных частиц для медицинских целей.

С.В. Шмаков, В.В. Клименко, С.В. Коняхин благодарят за финансовую поддержку Фонд „Сколково“ (Соглашение о предоставлении гранта российской образовательной и научной организации № 7 от 19.12.2017) и Сколковский институт науки и технологий (Генеральное соглашение о научно-исследовательской деятельности № 3663-MRA от 25.12.2017).

\section{Список литературы}

[1] Zhao D., Wan Y., Zhou W. Ordered Mesoporous Materials. Weinheim: Willey-VCH, 2013. 523 p.

[2] Vivero-Escoto J.L., Slowing I.I., Trewyn B.G., Lin V.S.-Y. // Small. 2010. Vol. 6. P. 1952-1967.

[3] Colilla M., González B., Vallet-Regí M. // Biomater. Sci. 2013. Vol. 1. P. 114-134.

[4] He Q., Shi J. // Adv. Mater. 2014. Vol. 26. N 3. P. 391-411.

[5] Advances in Nanotheranostics I. Design and Fabrication of Theranosic Nanoparticles / Ed. by Z. Dai. Berlin: SpringerVerlag, 2016. $336 \mathrm{p}$.

[6] Tang L., Fan T.M., Borst L.B., Cheng J. // ACS Nano. 2012. Vol. 6. P. 3954-3966.

[7] Cheng Z., Al Zaki A., Hui J.Z., Muzykantov V.R., Tsourkas A. // Science. 2012. Vol. 338. P. 903-910.

[8] Yano K., Fukushima Y. // J. Mater. Chem. 2003. Vol. 13. P. 2577-2581.

[9] Yamada Y., Yano K. // Micropor. Mesopor. Mat. 2006. Vol. 93. P. 190-198. 
[10] Трофимова Е.Ю., Курдюков Д.А., Кукушкина Ю.А., Яговкина М.А., Голубев В.Г. // ФХС. 2011. Т. 37. Вып. 4. С. 38.

[11] Yu M., Zhou L., Zhang J., Yuan P., Thorn P., Gu W., Yu C. // J. Colloid Interf. Sci. 2012. Vol. 376. P. 67-75.

[12] Trofimova E.Yu., Kurdyukov D.A., Yakovlev S.A., Kirilenko D.A., Kukushkina Yu.A., Nashchekin A.V., Sitnikova A.A., Yagovkina M.A., Golubev V.G. // Nanotechnology. 2013. Vol. 24. P. 155601.

[13] Kurdyukov D.A., Eurov D.A., Kirilenko D.A., Kukushkina J.A., Sokolov V.V., Yagovkina M.A., Golubev V.G. // Micropor. Mesopor. Mat. 2016. Vol. 223. P. 225-229.

[14] Tang F., Li L., Chen D. // Adv. Mater. 2012. Vol. 24. P. 15041534.

[15] Halas N.J. // ACS Nano. 2008. Vol. 2. P. 179-183.

[16] Garcia-Bennett A.E. // Nanomedicine-UK. 2011. Vol. 6. N 5. P. 867-877.

[17] Стовпяга Е.Ю., Еуров Д.А., Курдюков Д.А., Смирнов А.Н., Яговкина М.А., Григорьев В.Ю., Романов В.В., Yakovlev D.R., Голубев В.Г. // ФТТ. 2017. Т. 59. Вып. 8. C. 1598.

[18] Еуров Д.А., Курдюков Д.А., Медведев А.В., Кириленко Д.A., Yakovlev D.R., Голубев В.Г. // Письма в ЖТФ. 2017. T. 43. Вып. 15. C. 65-72.

[19] Eurov D.A., Kurdyukov D.A., Kirilenko D.A., Kukushkina J.A., Nashchekin A.V., Smirnov A.N., Golubev V.G. // J. Nanopart. Res. 2015. Vol. 17. P. 82.

[20] Еуров Д.А., Грудинкин С.А., Курдюков Д.А., Медведев А.В., Стовпяга Е.Ю., Голубев В.Г. // Письма в ЖТФ. 2015. Т. 41. Вып. 19. С. 1.

[21] Neginskaya M.A., Berezhnaya E.V., Rudkovskii M.V., Uzdensky A.B. // Proc. SPIE. 2014. Vol. 9448. P. 944800.

[22] Klimenko V.V., Knyazev N.A., Moiseenko F.V., Rusanov A.A., Bogdanov A.A., Dubina M.V. // Photodiagn. Photodyn. 2016. Vol. 13. P. 101-107.

[23] Klimenko V.V., Shmakov S.V., Kaydanov N.E., Knyazev N.V., Kazakov N.V., Rusanov A.A., Bogdanov A.A., Dubina M.V. // Proc. SPIE. 2017. Vol. 10417. P. 104170.

[24] Корнев А.А., Дубина М.В. // Рос. физиол. журн. им. И.М. Сеченова. 2014. Т. 100. Вып. 3. С. 257-273.

[25] Moise S., Céspedes E., Soukup D., Byrne J.M., El Haj A.J., Telling N.D. // Sci. Rep. 2017. Vol. 7. P. 39922.

[26] Lee S.-C., Fu C.-M., Chang F.-H. // Appl. Phys. Lett. 2013. Vol. 103. P. 163104. 